\title{
THOMAS DAVIS Y LA INVENCIÓN DE LA TRADICIÓN FENIANA
}

\section{Iñaki Vázquez Larrea}

Universidad Católica de Murcia

http://dx.doi.org/10.5209/rev_NOMA.2013.v38.42909

Resumen.- El presente artículo es una aproximación crítica a la poética de Thomas Davis, dentro de su contexto histórico, y de su contribución política a las coordenadas ideológicas del moderno movimiento republicano irlandés.

Palabras clave.- Irlanda, Fenianos, Thomas Davis, Banbha, gaélico

\section{Thomas Davis and the invention of the fenian tradition}

Abstract.- The current essay is an critical approach to the Thomas Davis poetry, within its historical context, and its political contribution to the ideological framework of the modern Irish republican movement.

Keywords.- Irlanda, Fenianos, Thomas Davis, Banbha, gaélico

"Ahora ya tenemos un movimiento literario. Esto no es muy importante. Vendrá seguido de un movimiento político. Eso no será muy importante. Entonces vendrá un movimiento militar. Eso es lo que será realmente importante ${ }^{1 "}$.

Standish James O'Grady

"Si a un hombre se le permitiese componer todas las baladas, no tendría que preocuparse de quién hace las leyes de la nación"

Alexander Fletcher, patriota escocés.

\subsection{IRLANDA TRAS EL ACTA DE UNIÓN DE 1801}

La principal consecuencia política del Acta de Unión, fue la certificación de la muerte de la "nación política protestante" irlandesa. Marcó el fin del monopolio del poder político de una Ascendancy (Ascendencia), que iniciaría un lento pero irreversible declinar a lo largo del siglo XIX. Curiosamente, fue el propio parlamento dublinés quien certificó su propia defunción, frente a la oposición vehemente de las logias orangistas, que en principio observaron el Acta de Unión como un ataque directo a los intereses protestantes en la isla.

\footnotetext{
${ }^{1}$ Citado por Standish James O’Grady, precursor del renacer literario celta en 1899.
} 
La Unión parecía la única alternativa plausible ante el sangriento enfrentamiento sectario de la década anterior, aún vivo en la memoria de los irlandeses. El Gobierno británico pretendía asegurarse que Irlanda dejase de ser un punto flaco en la retaguardia del Imperio, en caso de que la Francia revolucionaria acrecentase aún más su poder en el Continente. Por añadidura, la Unión con la Corona ofrecía mayores perspectivas de acomodación política a los católicos irlandeses, bajo el pertrecho de una "Carta Magna" que, aún salvaguardando el ethos protestante de las islas y de la propia monarquía británica, ofrecía más derechos y garantías constitucionales a los católicos que el Antiguo Régimen aristocrático irlandés, nacido tras el Tratado de Limerick en 1697, al amparo de las Leyes Penales contra presbiterianos y católicos irlandeses. A su vez, parecía dar respuesta a los intereses de un protestantismo irlandés, temeroso de verse sujeto a un status de minoría social, cultural y política en la isla, ante el creciente empuje de la clase media irlandesa.

Esta idea es defendida por el historiador irlandés D. G. Boyce: "La única alternativa seria al enfrentamiento y a las divergencias políticas típicas de la década de los 90, era la unión de ambos países bajo un único gobierno. Se pensaba que una constitución protestante podía acomodar las aspiraciones y reclamaciones de los católicos irlandeses, uniendo los recursos de ambos países dentro de la órbita Imperial británica" (Boyce, p. 19).

Para Conor Cruise O’Brien, el principal problema del Acta de Unión fue que no vino seguida de una total Emancipación Católica, y de medidas encaminadas a resolver el problema agrario, lo cual contribuyó, sin duda, a la definitiva división comunal sectaria de la política irlandesa en dos bloques antagónicos e irreconciliables; el Unionismo protestante, y el emergente nacionalismo católico irlandés (Conor Cruise O’Brien, p. 232).

Con todo, y a excepción del incipiente desarrollo industrial en el Ulster, Irlanda seguía siendo una sociedad rural. La extensa masa arrendataria católica vivía apegada a minúsculas parcelas de cultivo, bajo la constante amenaza de las famosas "evictions" o expulsiones, sometida al pago abusivo de rentas a la élite aristocrática propietaria protestante y la Iglesia de Irlanda (Iglesia anglicana), pese a que la mayoría de irlandeses profesaba la religión católica, situación que se perpetúa hasta 1869, cuando la Iglesia Anglicana pierde sus privilegios en Irlanda.

No es de extrañar, por tanto, que la violencia agraria fuera un mal endémico en la Irlanda post-napoleónica. El milenarismo jacobita de los Ribbomen o los Whiteboys, con esporádicas, pero constantes revueltas contra el pago de rentas, era un recordatorio de que, pese a todo, Irlanda seguía ocupando un "place apart" (un lugar especial) en el Imperio Británico.

Sin embargo, el principal fenómeno a subrayar en los primeros decenios del siglo XIX irlandés no es la violencia agraria, sino la creciente irrupción de una clase media católica, que reclama sin demora el derecho a la participación política. Esto es, el populismo católico de Daniel O'Connell, más conocido por el Liberador, y que logrará articular un auténtico movimiento de masas en torno a su persona. En la década de los 40 se añade a este último, un nuevo factor: el fortalecimiento definitivo de una Iglesia Católica que reclamará un necesario papel de censora y guía de cualquier movimiento socio/político católico de 
masas, en su vertiente populista o nacionalista. Tal política se verá refrendada en especial por el Cardenal Paul Cullen en la Irlanda post- Hambruna (1848), y será una constante en la vida política irlandesa hasta el Canto de Cisne del Partido autonomista irlandés de John Redmond, poco antes del psicodrama de la Rebelión de Pascua en 1916.

La asociación en pro de la Emancipación Católica fue creada por O’Connell en 1823. Esencialmente representaba los intereses de la gentry católica, y de grandes comerciantes de pequeñas ciudades como Waterford. Las coordenadas ideológicas del movimiento se situarían a caballo entre el populismo jacobita y una admiración no oculta por el utilitarismo y el constitucionalismo whig. El propio O'Connell se declaró gran admirador de las teorías de Bentham y Godwin, exaltando las virtudes del industrialismo y declarando un rechazo absoluto por los primeros balbuceos del sindicalismo industrial británico. Consideraba, a su vez, que la lengua gaélica no era sino "un residuo a extirpar en el mundo moderno".

Jamás barrunto la idea de restaurar una antigua arcadia gaélica, pero sí afirmaba pretender "devolver Irlanda a los irlandeses", por lo cual entendía "los católicos irlandeses".

Su principal virtud fue la hábil utilización de un lenguaje populista heredero de la antigua tradición jacobita irlandesa. La de la antigua élite nobiliar católica anglo-normanda, que a fines del siglo XVI decía luchar por Dios, el Rey de Inglaterra y la patria irlandesa. El declarar que el movimiento era "leal" a la Corona, al tiempo que nacional, le posibilitaba lograr contrapartidas políticas para la gentry católica a través de una férrea alianza con el constitucionalismo whig británico. Era ante todo, "un líder populista católico, jugando la carta católica" (R. Foster, p. 301)

Su populismo era el de una calculada ambigüedad cripto-sectaria. En ocasiones hablaba de la necesidad de "invadir el Ulster, para rescatar a nuestro pueblo en el Norte", al tiempo que no dudaba en describir una futurible Irlanda, como una teocracia católica unida a la Corona británica. Según sus propias palabras, una Irlanda "Rica, próspera, con una legislación devota a la verdad católica y a la autoridad" (J. N. Molony, p. 129). De hecho, este tipo de "misiones católicas" estuvieron a punto de hacer estallar un nuevo conflicto entre protestantes y católicos en el condado de Monaghan, septiembre de 1829, muy poco antes de que se lograse la Emancipación católica.

Para 1829, el año de la Emancipación, la psicología propia del protestantismo irlandés era la de una minoría a la defensiva. Su principal temor era el asentamiento de una Ascendencia católica, que desintegrara sus señas de identidad cultural y políticas. Baladas del periodo, como Protestant awake!!! (protestante despierta) son fiel reflejo de que el vigor de la clase media católica es observado como una clara amenaza a los intereses protestantes en la isla. La absoluta mayoría de los protestantes irlandeses se decían firmes defensores del Acta de Unión de 1801, como garante último de sus señas de identidad británico-irlandesas, de forma anterior, incluso, a la articulación del movimiento en pro de la Revocación del Acta de Unión en la segunda mitad de la década de los treinta.

En el Sur, la cultura política Unionista tendía a posicionamientos políticos, muy próximos al conservadurismo Tory. En el Ulster, predominantemente 
protestante, la penetración del fundamentalismo neo-reformista presbiteriano escocés, de la mano de Henry Cooke, junto con un creciente desarrollo industrial predetermina una revitalización de un lealismo orangista, firmemente comprometido con la defensa de la Unión.

Es en este contexto, donde un pequeño número de jóvenes intelectuales, publicistas y periodistas salidos del Trinity CollEge, formarán la Joven Irlanda. En principio. Con el firme propósito de crear un órgano literario que sirviese de apoyo al movimiento en pro de la Revocación del Acta de Unión de Daniel O'Connell, para venir posteriormente a sentar las bases ideológicas de la vanguardia militar nacionalista, y antecedente histórico del IRA, fundada por James Sthepen en 1858. La Irish Republican Brotherhood (IRB). Los fenianos irlandeses.

\subsection{Y A ESA RAZA DE HOMBRES LES SERÁ ENTREGADA IRLANDA}

"Adelante, adelante, sin detenerse, sin cesar nunca, sin buscar el momento de espera: sobre el homicidio, sobre el crimen, sobre todo obstáculo concebible, el espíritu romántico debe abrirse camino"

Goethe, Fausto.

"¡Cuanto tuvo que sufrir este pueblo para poder llegar a ser tan bello! $i$ ahora sígueme a la tragedia y ofrece conmigo un sacrificio en el templo de ambas divinidades!"

Nietzsche, El Nacimiento de la Tragedia

Quizás fue Alexis de Tocqueville, el intelectual que mejor supo captar y describir el ambiente social y político en el que surgió un reducido grupo de románticos nacionalistas irlandeses. Casi al mismo tiempo que Thomas Davis se licenciaba en el Trinity College en 1835, Tocqueville anotaba en su diario: "Esta Universidad fue fundada por la Reina Isabel con el dinero de las propiedades usurpadas a los católicos, los ancestros de los miserables campesinos irlandeses que frecuentemente vemos vagabundear. Esta Institución cuenta con casi cerca de 1.500 estudiantes. Muy pocos de ellos pertenecen a la clase adinerada irlandesa. La nobleza irlandesa vive en el extranjero. Gasta el dinero que produce en el extranjero. Incluso envía a sus hijos a Inglaterra, para que no se contagien de un vago instinto patriótico, que les pudiera unir a Irlanda. Si alguien desea conocer el significado del espíritu de conquista, del odio y sectarismo religioso, todo ello unido a los peores abusos aristocráticos, sin ninguna duda, que visite Irlanda". ( John.N. Molony. p. 14).

Efectivamente, ni Thomas Davis, ni John Dillon o Gavan Duffy, pertenecían al selecto grupo de familias adineradas irlandesas. Ellos, los futuros Jóvenes Irlandeses, tenían razones de sobra para rebelarse contra el utilitarismo, contra el racionalismo, porque el mar agrario irlandés, o el creciente provincianismo de la que fuera una capital regia, como Dublín, les condenaba necesariamente al ostracismo social y político. El Acta de Unión de 1801 seguía ofreciendo márgenes demasiado estrechos para la acomodación política y social de la pujante clase media católica irlandesa en las islas británicas. La preeminencia social seguía siendo ostentada por una oligarquía nobiliar terrateniente 
protestante, sobre la base de una estructura de propiedad agraria que aún recordaba en exceso los agravios inflingidos a los católicos durante centurias. El espectro de la proletarización en Belfast o Manchester resultaba aún menos atractivo para un Thomas Davis que provenía de una las familias aristocráticas protestantes de más renombre de la sureña ciudad de Cork.

Sobre el poeta romántico nacionalista que nace en 1814 , John O'Leary, el hombre que más influyó en la conversión feniana de W.B. Yeats, llegó a decir que: "Thomas Davis fue la fuente primaria, el origen de todo lo irlandés que existe en mí, por encima de todo, la inspiración que hizo de mí ser irlandés" ( Gavan Duffy, p. 34).

Lo cierto es el que el nuevo bardo o interprete de un nuevo pueblo celta, tiene una previa formación episcopaliana Tory, muy en línea con el luteranismo pietista o las doctrinas de Schelling o Hamman, que Isaiah Berlin considera como precursoras del movimiento romántico (Isaiah Berlin. p. 122).

Paradójicamente, el vitalismo individualista romántico, el mismo que exalta las virtudes del autodidacta al estilo de Goethe o el mismo que engendra la metáfora liberal barojiana de un Shanti Andia, adquiere un marcado tinte antiliberal y anti-humanista en Davis (Pío Baroja).

El patriotismo de Davis sólo concibe al individuo dentro de un marco orgánico continuo, determinado por Dios, y emanado a los irlandeses a través de la Historia. Dios ha escrito a los irlandeses un guión político que sólo los irlandeses con "conciencia patriótica" podrán y sabrán interpretar. La lengua gaélica, La Historia, la poética, la pintura irlandesa son el reflejo de una esencia nacional inmanente, que marca la pauta de un designio divino preescrito, al que el irlandés con "conciencia" ha de someterse; ya que el canto de Davis, es el canto de un abandono patrio, el de Irlanda por el pueblo gael. Un pueblo que sólo se redime y renace si se venga. Un pueblo que "sólo es irlandés", si hace la guerra con Inglaterra.

Davis, el gran admirador de Shelley y Carlyle, nos recrea un imaginario nacionalista propio de la metáfora clásica de Medea. La madre patria condenada a cabalgar eternamente sobre los cadáveres del opresor sajón. Tal y como el propio Davis nos lo expresa en una de sus poesías, The Harp (el Arpa), publicada en el semanario Citizen en 1841:

"Dios nos hizo libres, y a nuestro país una nación/ Los déspotas se han cansado con el designio del Todopoderoso/ Pero Erin mantiene orgullosamente su dignidad/ Primera en la lista de los felices y los libres".

En el caso de Thomas Davis, fueron Las Melodías Irlandesas de Thomas Moore, las que explican, al menos parcialmente, la conversión cuasi- paulina a la religión nacionalista ${ }^{2}$. Porque Davis, siempre interpretó el nacionalismo en

\footnotetext{
${ }^{2}$ Toda la poética de Thomas Moore viene marcada por una tensión dramática común. El llanto por la pérdida y la ruina de una inmemorial arcadia celta pagana, identificada con una especie de Edad de Oro irlandesa. El trazo orientalista, melancólico, y decadente del paisaje irlandés guarda claras reminiscencias byronianas. Este es el caso de poesías como "El Arpa que un día cruzo las colinas de Tara" o "Dejad que Erin rememore aquellos lejanos días". La Casta de guerreros celtas presentes en las leyendas de los Ciclos del Ulster es representada en sus poesías como modelo de virtuosismo patriótico. La poética de Moore propugna, a este respecto, un retorno a los valores de la mítica civilización celta pagana irlandesa. Véase, Poems of Thomas Moore (1982), Educational Limited Company.
} 
tales términos: "¿Hasta cuando pecaréis contra el patriotismo?", solía exhortar a los irlandeses ${ }^{3}$.

Al igual que Moore, Davis creía que Los Tories y los Whigs, "Los agentes de las Hordas de Bentham", estaban corrompiendo una Arcadia gael de raíz ossianica. La recreada por Macpherson, Carlyle, Agustin Thierry o Henry Hallan en su $A$ view of The State of Europe during the middle Ages (1818), de los que Davis tomó inspiración para recrear su concepción nacionalitaria. La influencia del historicismo racista celta de Thierry también es notable en sus primeras poesías.

A diferencia de Byron o Moore, Davis inscribe su romanticismo anti-racionalista dentro de un dualismo antagónico entre dos entes metafísicos. Irlanda, es la heredera de una civilización de esencia espiritual, donde la lírica celta bárdica es comparada con un ideal Homérico, y la grandeza de la nobleza guerrera celta con el status de semidioses de los héroes de la Grecia clásica. A los ojos de Davis, "los líderes de los clanes eran tan brutales como los semidioses de la Grecia clásica, gozando del apoyo de bardos cuya lírica era tan fiera y galante como la del propio Homero. La actual civilización mecanicista quiere exterminar nuestra herencia ancestral (Gavan Duffy)".

Inglaterra es para Davis el ente metafíco que encarna todos los males de la actual "civilización mecanicista" el Satán sajón que pretende exterminar nuestra esencia nacional celta, ahogar el canto de nuestros bardos, toda nuestra herencia ancestral.

"Toda esa sucia marea modernista. El moderno anglicanismo, el utilitarismo, la fe de Russell y Peel, y de los radicales. Llámalo yankeismo, llámalo anglicismo. Todo aquello que concibe la prosperidad como un mero intercambio de mercancías, reduce los límites del deseo al consumo de ropa, comida y respetabilidad. Toda esta maldición ha llegado a Irlanda de la mano de los Whigs y de los Tories". (D. George Boyce, p. 155).

Los irlandeses debemos "alzar nuestras espadas" contra Inglaterra, si queremos conservar nuestro ethos nacional gael; ya que de nuestro lado está el virtuosismo celta, y del de ellos, desde hace 800 años, "la culpa y el sajón". Este es el mensaje que Davis lanza a los irlandeses en una de sus poesías más famosas. The Song of O'Ruak: "Adelante sujetando la bandera verde de Erin/ Alcemos con energía las espadas/ de nuestro lado está la virtud y Erin/ Del suyo la culpa y el sajón" (Richard Davis, p. 237).

John Blake, el católico graduado en el Trinity College, sentía una particular veneración por Thomas Davis, ya desde los tiempos en los que Davis era presidente de la Sociedad Histórica de la Universidad. Al igual que a Gavan Duffy, les atraía la entrega total y la premura de un hombre que definía la poética de Moore como excesivamente abstracta e inconsistente, y que consideraba como una cuestión de vida o muerte la articulación de una cultura popular nacional, hasta aquella fecha inexistente.

\footnotetext{
${ }^{3}$ En 1843, Thomas Davis afirma: "La tierra no es lo suficientemente profunda para esconder al esclavo cobarde que se echa atrás. El infierno no es suficiente castigo para aquel que renuncia a su fe. Por honor, orgullo y política, por Dios mismo, debemos ser libres. Nos jactamos y juramos, que romperíamos las cadenas de nuestro país o pereceríamos, y deberíamos temblar solo con la idea de que el nombre de nuestro país fuese sinónimo de vergüenza". En J. Molony (1995), A Soul came to Ireland, Geography publications, Dublín, p. 208.
} 
El ejemplo de Thomas Davis casa bien con la tesis de Benedict Anderson sobre el origen y difusión de la Ideología nacionalista. A saber, la estrecha interacción entre un estadio socio-económico precapitalista, y la difusión de una "memoria nacional" anteriormente inexistente (Benedict Anderson, p. 1991). Duffy, al igual que Davis, consideraba que "los hechos históricos hablaban por sí mismos", aunque para ello tuvieran que echar mano de intelectuales e ideólogos contrareformistas postbárdicos del siglo XVII irlandés, al estilo de Keating, o incluso anticuarios protestantes del siglo XVIII, como Silvester O'Halloran, quienes nunca consideraron que los "hechos históricos hablasen por si mismos". Se trataría, más bien, de arquetipos nacionalistas que tienen la firme creencia de que su tarea consiste en "iluminar la Historia a contrapelo", en palabras de Walter Benjamin. Al menos esa era la intención del periódico The Nation, fundado por Davis, Dillon y Duffy en septiembre de 1842. El crear "una raza de irlandeses apegada a su tierra", sobre la base del legendismo y el mito de la balada histórico popular.

La Historia y la Poesía delimitan una única senda política de corte nacionalista a los irlandeses, un pensamiento unidimensional: "Impregnar nuestro espíritu de la memoria de los grandes hombres, que serán a su vez el modelo de nuestra conducta y nuestros jueces. Esa es la labor de la Historia, y ésta se enseña mucho mejor en forma de balada" ( John N. Molony, p. 145).

The Nation llegó a alcanzar una tirada de cerca de 250.000 ejemplares en una Irlanda de cerca de ocho millones de habitantes, de los que casi un 50\% era analfabeta. Su mensaje iba dirigido esencialmente a la clase media católica. No en vano, se concibió, en parte, como un órgano literario propagandístico dependiente del movimiento en pro de la Revocación del Acta de Unión liderado por Daniel O'Connell, que alcanzaría su punto culminante, y canto de cisne, en 1843, con las famosas "manifestaciones monstruo", y al que Davis dedicará una de sus poesías más famosas, The West Asleep

(El Oeste Despierta). "Cantemos hurra, que Inglaterra tiemble", dice la tonadilla repetida hasta la saciedad por futuras generaciones de nacionalistas irlandeses, entre ellos, el padre de Frank McCourt, en su cenit de borrachera alcohólico/nacionalista, en Las Cenizas de Angela. (Frank McCourt, p. 123).

El drama del padre de Frank, como el de W. B. Yeats o Thomas Davis, fue el mismo que el de gran parte de irlandeses protestantes, que predicaron las virtudes de un imaginario nacionalista etnocentrista y anglófobo. Davis reconocía predicar desde "el exilio" en 1843, a cuenta de la incomprensión y rechazo que inspiraba su mensaje en su familia y vecinos protestantes. Yeats, más arrogante, desde la Torre poética en 1938, se quejaba del desdén con que De Valera y la Iglesia católica trataron a la élite protestante anglo/irlandesa tras 1921, mientras que, al mismo tiempo, la caridad católica del Estado Libre de Irlanda le decía a la familia de Frank que buscase ayuda en "sus amigos orangistas de Belfast". A su padre, el mismo que les extraía la promesa diaria de "morir por Irlanda, en el glorious IRA!!!".

Ensalzar las virtudes de un ente étnico suprahistórico, gael y anglófobo para más señas, era partir de la presunción de que "el pueblo real" de Irlanda, el

\footnotetext{
${ }^{4}$ Silvester O'Halloran. Anticuario e Historiador protestante irlandés. En 1785 funda la Royal Irish Academy of History.
} 
histórico eran los católicos irlandeses, y que los protestantes defensores de la Unión con Inglaterra no lo eran tanto, o que al menos deberían ser nacionalistas, para poder ser irlandeses. Davis exige a los protestantes irlandeses la "conversión a la fe patriótica, que redescubran su verdadera irlandesidad", que vuelvan a la cultura política de Tone, Grattan, Swift y Molineaux. Una cultura política ya muerta en la Irlanda del periodo. De esta forma, el llamamiento a la guerra contra Inglaterra de Los Jóvenes Irlandeses, habría de traducirse necesariamente en una guerra civil irlandesa. Para Davis, los descendientes de Cromwell en Irlanda, estirpe a la que él mismo pertenecía "son el segmento de población más anti-irlandés. No tienen ningún remilgo a la hora de deshonrar a su país. Un crónico sentimiento de inseguridad les hace entrever que es su deber y obligación degradar, humillar y maltratar al pueblo irlandés". Al partir de estas premisas podríamos advertir que los protestantes lealistas del Ulster, al no asumir las virtudes de la ideología nacionalista, "dejan de ser irlandeses". Además "maltratan al pueblo irlandés"; esto es, a los católicos irlandeses. Los protestantes (planters) al parecer, no forman parte del pueblo irlandés. Davis, a continuación, les exige la conversión a la religión nacionalista para poder ser irlandeses: "Deben ser diferentes de lo que son. $A$ ellos también les queremos. Necesitamos de su ayuda ahora. Por ellos mismos, por su país" (Gavan Duffy, p. 233)

Esta miopía nacionalista tenía, no obstante, una explicación en Thomas Davis. Para él, como para Yeats, el esencialismo celta podía generar un sistema de alianzas políticas que superasen la división religiosa en la isla. Al tiempo que la anglofobia podía amortiguar el trauma de su papel político dirigente en Irlanda, tras el Acta de Unión de 1801, ante la perspectiva de verse líderes de una clase media católica, susceptible a la movilización social en base a la "eterna cultura del agravio inglés".

La clave del éxito, y a su vez la mayor debilidad, del movimiento en pro de la Revocación del Acta de Unión de 1801, fue que nunca postuló un modelo político alternativo. O'Connell se limitaba a azuzar el recuerdo de la derrota católica en la batalla de Boyne (1690), saludando al mismo tiempo la llegada al trono de la Reina Victoria en 1837. Dicho populismo se mostró eficaz a la hora de movilizar a amplios sectores de la sociedad católica irlandesa, en especial a comerciantes y propietarios agrarios católicos (las manifestaciones monstruo llegaron a aunar a cerca de 300.000 personas en 1843), pero chocaba con los propios límites y las ambiciones de un movimiento que veía cómo ahora podía enviar parlamentarios católicos irlandeses al corazón de un Imperio cuyos cimientos parecían más inmutables que nunca. En 1834 sólo 38 de los 523 parlamentarios británicos votaron a favor de la Revocación del Acta de Unión. El dato a tener en cuenta es que de entre ellos, una exigua minoría de parlamentarios irlandeses votó a favor. Sin duda, un tremendo golpe para un O’Connell que proclamaba ser líder de la "nación irlandesa" (D. George Boyce, p. 145).

Con el tiempo, La Joven Irlanda, el nombre con el que se empezaba a conocer al grupo de intelectuales encabezados por Davis, comenzó a distanciarse del Liberador, mientras que el movimiento en pro de la Revocación del Acta de Unión perdía vigor ante la falta de horizontes políticos. A diferencia de O'Connell, Thomas Davis era proclive a una Irlanda federal, como tránsito previo hacia una Irlanda Independiente. Ello frente a los males del 
"industrialismo sajón", que provocaría "la conversión del afectuoso, natural y creyente irlandés en un animal John Bull ", Davis defendía la posible articulación de una idilia de pequeños propietarios agrarios a la Noruega.

Era también hostil al criptosectarismo católico defendido por O’Connell, sobre todo en el ámbito educativo. Además no rechazaba la utilización de la violencia y observaba la necesidad de confrontar la oposición protestante al nacionalismo romántico irlandés.

En 1843, Davis entra en contacto con la Filosofía de la Historia de Schelegel, y con el Address to German Nation (Ilamamiento a la nación alemana) de Fichte. Esta última obra, junto a la confesada fascinación por Carlyle y Ruskin, marcarán decisivamente la concepción nacionalitaria de Davis en los últimos años de su existencia. De hecho, pocas semanas antes de su muerte, acaecida en febrero de 1845, Davis recomendó la lectura de Fichte a su prometida, Annie Hutton.

Ello determina una noción aún más agónica y esencialista de la nación irlandesa, concebida como una entidad ahistórica, natural o persistente. El gaélico pasa a ser el trasmisor natural de un carácter nacional inmutable, de un ethos nacional gaélico y anglófobo. Por tanto, la muerte del gaélico equivale a la muerte de la nación irlandesa. En su Our National Language (1843), nuestra lengua nacional, nos dice: "Un pueblo sin su propia lengua, es sólo mitad nación. Una nación debería proteger su lengua más que sus propios territorios. Es una barrera y una frontera más segura que los fuertes y los ríos. Es más, perder tu lengua nativa y aprender una extranjera, es la marca más vergonzosa de conquista, encadena el propio espíritu nacional. El perder totalmente la lengua nacional es la muerte. La lengua y las leyes irlandesas iban unidas a un pasado común. La nación era un colectivo diferente al del Estado, por lo tanto la nación irlandesa ha existido durante siglos, si bien nunca ha adquirido forma de Estado". (Richard Davis, p. 235).

El arte, la poética, la Historia son las claves para entender e interpretar "lo que cantaron los bardos gaélicos". Ya que Davis, como intérprete que asume una conciencia de autorrealización ascética patriótica, identifica sus creencias políticas con la necesaria plasmación de un cuadró artístico total. Este ideal es defendido de la siguiente forma en The Voice of The Nation (La Voz de la Nación) en 1844: "La nacionalidad reclama una Literatura irlandesa revestida por nuestro paisaje, costumbres y carácter. El arte habrá de estar orientado a expresar creencias y pensamientos irlandeses. De esa forma, la nación creará una raza de hombres imbuida de conocimiento y carácter específicamente irlandés, y a esa raza le será entregada Irlanda" (J. Molony, p. 297).

En Davis, es una raza de semidioses clásicos los únicos llamados a guiar e interpretar "las creencias y los pensamientos de todos los irlandeses", de trazar e iluminar un designio político delimitado de antemano por Dios y por la Historia, "solo a esa raza de hombres le será entregada Irlanda".

\subsection{VENGANZA ÉTNICA Y REDENCIÓN PATRIÓTICA: EL ETERNO LAMENTO POR LA MUERTE DE OWEN ROE O'NEILL}

La nueva raza de semidioses clásicos de Thomas Davis, está además abocada a una eterna tragedia dionisiaca. La balada Histórica de Davis se configura 
sobre la base de una secuencia dramática constante. El soldado/poeta nacionalista, el héroe nacional en armas, salvaguarda "los derechos históricos" de Irlanda, que emanan de Dios. La muerte del héroe, sirve a su vez, para la resurrección esencialista de una Irlanda que yace postrada, agónica, corrompida. La guerra contra Inglaterra es el acto más sublime de heroísmo patriótico. El pueblo de Davis, se muestra entonces como es, como debería ser. Se venga, se redime y sobrevive.

Tal y como defiende Richard Davis, "puede que Davis desease evitar una guerra pero su mente estaba llena de imágenes de guerra, para convertirse enseguida en un brillante estratega militar" (Richard Davis, p. 50). Idea que, de hecho, nunca rechazó el propio Davis, para el que "existe más nobleza y heroísmo en la guerra que en ninguna otra actividad humana" (J. Molony, p. 204). Las manifestaciones monstruo de O'Connell eran de hecho interpretadas en clave militarista y anglófoba. En diciembre de 1842, Los Repealers reunidos en Tipperary serían para Davis: "una excelente Guardia Nacional para Irlanda", al tiempo que "parenciase prestos a redimir a su pueblo a cualquier coste" (John Newsinger, p. 23).

A partir de 1843, The Nation publica la serie de Baladas Nacionales, que tanta popularidad alcanzará en futuras generaciones nacionalistas. Las dos primeras baladas son The Memory of the Dead (La Memoria de Los Muertos), Davis recupera la temática de la revuelta de 1798. La guerra contra Inglaterra se convierte en un modelo de virtud patriótica a imitar: “¿Quien teme hablar de 1798?/ ¿Quién se sonroja al oír su nombre?/ Es un bellaco y mitad esclavo/quien insulta a su país de esta forma". En mayo de 1844, Davis ofrece su devoción a la tumba de Wolfe Tone. Irlanda ha abandonado los ideales de Wolfe Tone y su tumba se encuentra en "ruinas y en penumbra", sólo cuando Irlanda se alce en armas contra Inglaterra podrá reconstruir "su tumba". Los irlandeses deben seguir el ejemplo del "devoto mártir". La guerra contra Inglaterra supone la resurrección de una Irlanda, que al igual que la tumba de Wolfe Tone, "vuelve a reverdecer"...

De esta manera integra Davis el republicanismo liberal de Tone dentro de La Tradición feniana: "Un mártir de Irlanda/ Su tumba no tiene lápida, apenas es nombrada/sus virtudes son desconocidas/Le honra más la ruina y la penumbra, hasta que Irlanda, una nación libre, le reconstruya su tumba" (J. Molony, p. 236).

Pero quizás sea The Song for an Irish Militia (Canción para una milicia irlandesa), la que ofrezca la génesis más acabada de la futura guerra feniana. Escrita a principios de 1845, poco antes de su muerte, pretendía servir de canto patriótico para las futuras milicias de voluntarios, que ante el fracaso del movimiento en pro de la revocación del Acta de Unión resucitarían el viejo espíritu nacional del Parlamento de Henry Grattan: " The tribune's tongue and poet's pen/ may sow the seed in prostcate men/but it is the soldier sword alone/ Can reap the crop so bravely/ No more I will sing nor idly pine/But train my soil to lead a line/ A soldier's life the life for me/ A soldier death, so Ireland's free!!!".

El mensaje es el siguiente. La poesía sirve para cultivar el espíritu nacional irlandés, pero resulta en vano, si no produce una vanguardia militar nacionalista, que defienda los derechos nacionales emanados por Dios. Literalmente: "sólo la espada del soldado puede recoger la cosecha. Jamás 
volveré a cantar en vano, sino que enseñaré a mi patria a desfilar. Dadme la vida de un soldado, la muerte de un soldado para que Irlanda sea libre"

La muerte del soldado en guerra con Inglaterra es lo que en última instancia resucita a madre patria que yace agónica, postrada. "Dadme la muerte de un soldado, para que Irlanda sea libre". La misma idea es repetida en el himno no oficial de la Irlanda nacionalista, A Nation Once Again (julio de 1844); fragmentos poéticos que aún hoy día son escritos en los murales republicanos de Irlanda del Norte: "Porque la libertad es otorgada por Dios, algún día un grupo selecto de hombres, hará otra vez de nuestra tierra, una única nación"

De todas ellas, no obstante, El Lamento por la Muerte de Owen Roe O'Neill (1844) es la balada histórica que merece un análisis más riguroso y detallado. En primer lugar, por su evidente influjo en futuras generaciones de nacionalistas. Sobre "Lament" Yeats, llegó a afirmar que Thomas Davis "estaba de luto, no como poeta, sino como hombre por la tristeza de Irlanda". En segundo, por lo trascendente de la reinvención del mito histórico presente en el fragmento lírico, típico por otra parte del romanticismo europeo de la primera parte del siglo XIX. En tercer, y último lugar, por la estrecha vinculación entre creación literaria y mito nacionalista. Una constante en el nacionalismo cultural irlandés, a partir de Thomas Davis.

En la balada, Thomas Davis retoma un recurso poético propio del Antiguo Orden Gaélico irlandés, desaparecido tras la batalla de Kinsale (1601) y la huída de los nobles gael del Ulster en 1607. El bardo celta describe el llanto y el abandono de Irlanda, antes de la caída en desgracia del aristócrata gael.

Thomas Davis tuvo acceso a la poesía postbárdica de mediados del siglo XVII, en particular de la del ideólogo Contrarreformista Keating, de la que "Lament" es un calco. Davis retoma una vieja leyenda del siglo XVII irlandés, por la que Owen Roe O’Neill

(Eoghan), junto con Rory O’Moore, uno de los líderes más carismáticos de La Confederación Católica, muere envenenado por "traidores irlandeses", poco antes de entrar en batalla con el ejército puritano de Cromwell en noviembre de 1649:

"Si hubiera vivido, Si hubiera vivido/ Nuestro país hubiera sido libre/ Pero está muerto/y seremos esclavos para siempre/Pensábamos que no te morirías/seguros de que no te irías/ y dejarnos indefensos frente al cruel designio de Cromwell/ rebaño sin pastor, cuando cae la nochel ¡Oh! ¿Por qué nos dejaste Eoghan?/ ¿Por qué te moriste?". El cruel designio de Cromwell no es otro, que el haber dejado una Irlanda celta en manos de Inglaterra.

La pregunta clave es ¿Quién era Eoghan?, y sobre todo, ¿A quién abandonó Eoghan? Para comprenderlo, Michelle O'Riordan nos ofrece un interesante estudio sobre la concepción identitaria de la sociedad gael a través de la poética bárdica desde el siglo XII, hasta su práctica desaparición a principios del siglo XVII. O’Riordan observa que: "Gran parte de la poesía bárdica de los siglos XIII y XIV conserva un ritual estilístico y una temática muy semejante a la de principios del siglo XVII. La temática de "Banbha" (Irlanda) en peligro, y la del guerrero que rescatará y unirá Irlanda en contra de sus enemigos, son una constante, y no pueden interpretarse desde una óptica nacionalista contemporánea" (Michelle O’Riordan, p. 23). 
En la Irlanda pagana celta, la existencia del file o poeta encontraba su lógica en la necesaria vinculación de su creación poética con un sentido de continuidad histórica de los hechos, determinada por el mito originario del Leabhar Ghabhala o Libro de las Invasiones, por el que Irlanda (deidad femenina), se vería abocada a cíclicos raptos o takings, desde que el 3.500 a $\mathrm{C}$, tras la dispersión babélica, el rey celta de España, Mill, descendiente del escita Fenius, diera con sus huesos en la isla.

Esta será la identidad sincrética de la Irlanda monástica de la Alta Edad Media. Posteriormente, la poética bárdica, sobre todo a partir del siglo XII, coincidiendo con el asentamiento de formas de poder proto feudales en la sociedad gaélica, presentará un tono eminentemente panegirista. Esto es, la exaltación y legitimación del poder del aristócrata gael, sobre una base genealógica inventada y vertebrada sobre el mismo mito originario celta/babélico del Libro de las Invasiones.

El bardo presenta un modelo eulogístico constante. Irlanda como deidad femenina, noción poético/ espiritual (que no política), espera ser sometida o seducida por el jefe del clan o guerrero más poderoso de la isla. Cuanto mayor es el poder del chief o jefe del clan, mayor la fertilidad y la felicidad de Banbha, que mantiene una vinculación pseudomarital con el noble gael. La muerte agónica de Banbha es un recurso poético que sirve para en ensalzar el gran poder que ostentó el noble guerrero muerto en batalla o caído para siempre en desgracia. Esta era la psyche identitaria, de una sociedad eminentemente aristocrática y localista, representada metafóricamente a través de una poética, que poseía una evidente funcionalidad política. Además, el estudio de O'Riordan ofrece otros detalles de sumo interés. Observa la existencia de un recurso eulogístico/genealógico idéntico en poetas bardos que ofertaban sus servicios a la aristocracia anglo/ normanda desde el siglo XIV.

Aquella misma aristocracia que vivía desde el siglo XII apegada a los privilegios otorgados por el Señorío inglés, pero cuyo poder no se extendía más allá de los alrededores de Dublín o Pale, y que para el siglo XIV ya había entrado en convergencia política y cultural con el preeminente Orden Gaélico.

Lo relevante al caso, es que la utilización de un mismo recurso eulogístico/genealógico muestra, a su vez, que la noción de etnicidad gael iba desligada de cualquier sentimiento anglófobo. Los gael tenían la noción clara de ser "Invasores" de Irlanda, de una Erin sojuzgada y sometida a un Orden gaélico preeminente.

De ahí, que la política de plantaciones instigada por Isabel de Inglaterra y Jaime I a principios del siglo XVII, no fuera concebida por el Orden Gaélico como una política de colonización, sino como uno de los cíclicos y numerosos raptos que venía sufriendo Banbha desde los tiempos de la dispersión babélica. Esto explica, parcialmente, la alianza política de muchos nobles gaélicos con la Corona en Irlanda a partir de 1541, fecha en que Enrique VII se declara rey de Irlanda e Inglaterra, así como la ausencia de vínculos de solidaridad política interétnicas o nacionales, ante el empuje colonial inglés, así como su rápida extinción tras la derrota de Kinsale en 1601.

El Clan de la Mano Roja de Hugh O’Neill, bisabuelo de Owen Roe O'Neill, nos ofrece un arquetipo ideal de lo mencionado anteriormente. En principio, el noble más poderoso del Ulster fue fiel aliado de Isabel de Inglaterra, frente a 
otros clanes gaélicos más proclives a ofertar sus servicios al Imperio de Felipe II. En 1590, por el contrario se declara fiel súbdito de su majestad Imperial española ante la promesa de la garantía de un Palatinado en el Ulster, bajo cobertura política hispana. En 1598, O’Neill derrota a las tropas de Isabel de Inglaterra en Yellow Ford, hasta que en 1601 es definitivamente derrotado en Kinsale. Posteriormente, Hugh O'Neill gana de nuevo el favor de Jaime I, El Estuardo de origen escocés, tras el Tratado de Millifont en 1603, por el recupera además sus derechos sobre el Señorío del Ulster.

En 1607, sintiendo su posición política amenazada, huye del Ulster, acompañado de otros nobles gaélicos. Según la Leyenda, Hugh O’Neill murió pocos años más tarde en España, absolutamente abatido por la deshonra y la melancolía.

Lo cierto es que las extrañas circunstancias de la huida y el rastro del canto agónico del bardo, que certifica la muerte de Irlanda ante la huída de los Wild Gesse o gansos salvajes (nombre con el que se conoció a la nobleza gaélica en el exilio tras su derrota en las sucesivas guerras isabelinas) excitó sobremanera la imaginación de muchos patriotas irlandeses en el siglo XIX, incluída la del propio Thomas Davis que dedicó más de un poema al suceso, y que veían en O’Neill un patriota irlandés derrotado por Inglaterra; si bien O’Neill siempre dejó claro que sus ambiciones políticas no pasaban de la instauración de un Palatinado en el Ulster..

Tal y como nos recuerda un gran estudioso de la Irlanda moderna, Roy Foster: "El Ulster era el ámbito sobre el que O'Neill pretendía asentar su poder señorial, careciendo además del apoyo de otros clanes gaélicos del resto de Irlanda. La teoría de que aquellos que lucharon con O'Neill lucharon por Irlanda, se basa en la retórica utilizada por el lenguaje poético bárdico. Un lenguaje poético sujeto, por otra parte, a las convenciones de expresión tradicional y concepción de la Historia propias del Antiguo Orden aristocrático tradicional localista gaélico. La Ideología de la Contrarreforma, absorbida a través de los canales establecidos con la Europa católica, ayudará a cambiar esto. A mediados de siglo es evidente la fusión de catolicismo y patriotismo en intelectuales como Keating. Resulta debatible si se le podría denominar como nacionalismo. Ante todo, la obra de Keating y otros, vino determinada por la necesidad de dar un sentido histórico a lo que estaba pasando en Irlanda" (R. F. Foster, p. 213).

Lo que estaba sucediendo en Irlanda era la práctica extinción del Antiguo Orden gaélico. Jaime I extendió las plantaciones, colonos protestantes provenientes de Inglaterra y Escocia al Ulster en 1609, tras la desaparición del poder nobiliar gaélico en la zona. Tal política fue mantenida por su sucesor Carlos I, hasta el punto de que en 1640 sólo un 40\% de las tierras de Irlanda se hallaba en manos de aristócratas católicos. Jaime I instigó dicha política bajo la idea de que, como afirmó en 1613, "Los súbditos católicos de Irlanda son más fieles al Papado que a la Corona inglesa" (D. George Boyce, p. 109). La política de protestantización de la isla, por tanto, salpicaba también a la aristocracia anglo/ normanda que empezaba a tener serias dificultades para defender que su catolicidad era compatible con la fidelidad a la Corona inglesa. Una Corona, no olvidemos, protestante, que veía con creciente temor y preocupación la guerra que el Imperio Católico de los Habsburgo y el Papado 
habían declarado a la Reforma luterana; el inicio de lo que luego vino a denominarse como La Guerra de los Treinta Años.

Así las cosas, comienzan a gestarse crecientes vínculos de solidaridad política entre la casi extinguida vieja nobleza gael (Old Irish) y la anglo/normanda (Old English), sobre la base de un común denominador, la religión católico romana. En Inglaterra, la pugna entre el republicanismo puritano radical de Cromwell y la monarquía de Carlos I, desemboca en una guerra civil, en la que los irlandeses de diferente confesión religiosa tomaran parte. Poco antes, en 1641, el estallido de una rebelión de la aristocracia católica, se cobrará la vida de cerca de 2.000 colonos protestantes en el Ulster (fecha conmemorada aún por el Unionismo en Irlanda del Norte). El suceso servirá de catalizador para la polarización político/religiosa en la isla. Mientras los colonos protestantes apoyan el republicanismo parlamentario de Cromwell, la inmensa mayoría de la aristocracia católico irlandesa tomará partido a favor de la conservación de la prerrogativa regia de Carlos I.

Bajo el pertrecho de la jerarquía católica, en especial de los Jesuitas, se crea en 1643, la Confederación Católica, cuyos principios fueron establecidos en la Declaración de Dungannon de octubre de 1641: "No hemos tomado las armas en contra del rey, tampoco pretendemos herir a sus leales súbditos de la nación escocesa o inglesa; sino por la defensa de nuestras libertades y la de los nativos de la nación irlandesa. El parlamento inglés pretende acabar con la religión católica en la isla y las gracias recibidas por nuestra nación, usurpando la prerrogativa regia de su majestad Carlos I"( D. George Boyce, p. 123)

La defensa del favor de la Corona inglesa, con el objeto de invertir el proceso de perdida de posesiones nobiliares, y la de la religión católica, fue el sostén básico de la alianza nobiliar católica irlandesa en 1643. Es cierto, no obstante, que existieron disensiones en su seno. Parte de la antigua nobleza gaélica, que había combatido en su exilio en el Continente, se había imbuido de un mayor celo Contrarreformista, y como el propio Owen Roe O'Neill, era, ciertamente, más fiel al nuncio papal en Irlanda, el Cardenal Rinuccini, que a Carlos I, aunque la mayor parte de los casos ello no era incompatible con el mantenimiento de un fervoroso realismo, hasta la derrota final Confederada en 1649.

La poesía postbárdica del periodo mantiene recursos y convencionalismos propios del Antiguo Orden Gaélico, aunque la estirpe poética barda desapareció con la Orden, pero también ofrece variantes significativas. Irlanda es ahora una deidad femenina que camina junto a la virgen María; el viejo esquema secular poético gaélico desaparece. Irlanda como deidad católica, que yace abandonada o moribunda, tiene que ser rescatada por y para el gael contra sus enemigos, el extranjero herético/protestante o el sajón de habla extranjera o Sassenach. Dicho imaginario se encuentra representado en numerosas seanchas anónimas del periodo. Una balada poética Confederada fechada en 1644 nos dice:

Pronto los héroes se reunirán/uniéndose mano en mano/para derrotar a los extranjeros en Saingel y Mullaghmaistin/entonces nadie se aliará con los sajones y semi desnudos escoceses/ Es entonces cuando Erin será libre/ Es entonces cuando perecerá la lengua sajona/ Los gaels en armas triunfarán, sobre la falsa y herética secta de Calvino" (D. George Boyce, p. 84) 
Este imaginario aparece de forma más estlizada en la poesía del Ideólogo contrarreformista irlandés por excelencia del periodo, Geoffrey Keating. En An Siogai Rombanach, poema que exalta las virtudes del líder Confederado Owen Roe O'Neill, Irlanda es comparada con un icono católico amenazado por los extranjeros protestantes. El poema acaba con un ruego: "Ruego a Dios, la Virgen María, y al Espíritu Santo que llegue el día en que los gael se unan y expulsen a los extranjeros para que Banbha sea libre" (Joseph Leersen, p. 218).

Owen Roe O’Neill nunca pudo cumplir el vaticinio de Keating, ya que murió enfermo, que no envenenado como contará la leyenda. Es dudoso, por otra parte, que este imaginario nativista anti-protestante pueda definirse como protonacionalista. La poesía postbárdica no puede dejar de entenderse si no es dentro del contexto global de la guerra europea de los treinta años; además como se ha señalado anteriormente, su contrarreformismo aparece mezclado con viejos arquetipos poéticos de la extinta sociedad gaélica.

En cualquier caso, esto es lo que abandonó Owen Roe O'Neill, o lo que no pudo ganar para los gael. Una Irlanda aristocrática, católica y anti-protestante, leal a su majestad Carlos I de Inglaterra. Un ideario próximo al que defendieron los aristócratas católicos irlandeses que apoyaron la sucesión al trono de Jaime II de Inglaterra, definitivamente derrotados en Irlanda a orillas del río Boyne, un 12 de julio de 1690, y popularmente conocidos como jacobitas.

El lamento de Thomas Davis es de otra índole. O 'Neill nos abandonó a nosotros, los gael en guerra contra Inglaterra. Irlanda yace moribunda desde entonces, el abandono celta exige sangre, venganza y redención patriótica, no ya contra la secta de calvino, sino contra Inglaterra. Contra Inglaterra sí, pero también contra los que lo envenenaron, los traidores, los que no comparten la fe patriótica del héroe nacional en armas, y del bardo que le canta, en este caso Thomas Davis. En realidad Davis estaba haciendo un llamamiento a la venganza étnica, la del nosotros ahistórico gael contra Inglaterra y los aliados de esta en Irlanda, en la práctica una guerra civil. Porque es hacer la guerra contra Inglaterra, el sustantivo, la esencia misma, lo que configura ese nosotros, que ha de pervivir por encima y en correlación a las leyes de la Historia. Y es que, como diría, el antropólogo Mikel Azurmendi, la venganza étnica puede no tener fin, puede llegar a ser eterna (Mikel Azurmendi, p. 63).

No en vano, lo que Thomas Davis deseaba para aquellos que envenenaron a Owen Roe O'Neill era que. "Dios les destrozase los corazones/ que su sangre nunca dejase de ser derramada/que caminasen en la eternidad como muertos vivientes".

Tras la prematura muerte de Thomas Davis, debido a crónicos pero nunca resueltos problemas de salud, a principios de 1845, el resto de Irelanders, encabezados por John Mitchell y Smith O’Brien, fundarán los Confederados Irlandeses (1846). En su seno podemos encontrar a futuros miembros de la IRB (Irish Republican Brotherhood), como John O’Mahony o James Stephen, así como intelectuales, de la talla de Fintan Lalor o Magan. El objetivo de todos ellos, desde su órgano de expresión, The United Irishmen (Los Irlandeses Unidos) es claro, planear y dirigir una insurrección militar contra Inglaterra.

Los acontecimientos de la Francia revolucionaria y la poesía de Lamartime sirvieron de guía a Los Confederados, que creían poder trasladar el ejemplo 
continental a Irlanda. Si bien a principios de 1848, cuando la Gran Hambruna comienza a cobrarse decenas de miles de vidas, los ex/Irelanders, apenas contaban con una decena de simpatizantes. El paisaje agrario irlandés se pobló en pocos meses de una legión interminable de campesinos hambrientos que buscaban la salida del país en los famosos coffin boat (barcos ataúd) con destino a Estados Unidos. El país entero se movilizaba para paliar los efectos de la catástrofe, mientras el iluminismo patriótico de los secuaces de Davis planeaba un gesto militar, que desembocaría en la instauración de una República irlandesa independiente.

La escaramuza de Ballyngarry, como se conoció la insurrección de 1848, presenta los rasgos tragicómicos de los coup $d$ état propios de las sociedades secretas decimonónicas, inspiradas por Manzini o Blanqui. Su mesianismo revolucionario les impedía ver que su gesto sólo resulta ser importante en la mente de aquellos que lo protagonizan, dentro de un universo puramente narcisista.

Como John Mitchell, el hombre que más tarde popularizaría la versión de la Gran Hambruna como un genocidio inglés. Mitchell, encarcelado por su participación en la insurrección, comenzó su Diario desde la cárcel, con el mismo ruego de Lament: "Oh Dios, danos una guerra contra Inglaterra en nuestro tiempo" (D. George Boyce, p. 120).

La semilla de Thomas Davis no tardaría en dar sus frutos, pero por aquel entonces la extinción social (por emigración o muerte) de la masa arrendataria católica y el fracaso del Movimiento liderado por O’Connell, parecía fortalecer, más que nunca, los cimientos del Acta de Unión en Irlanda.

\subsection{LA VANGUARDIA PATRIÓTICA DE JAMES STEPHEN: LA CREACIÓN DE LA IRISH REPUBLICAN BROTERHOOD (IRB)}

"Las ejecuciones de Manchester de 1867 han supuesto el acta final de separación entre Irlanda e Inglaterra. Lo único de que carecían los fenianos eran mártires. Inglaterra, finalmente, se los ha proporcionado".

Federico Engels

Sería difícil imaginar la eclosión de la IRB, sin atender a la prosperidad económica de las islas británicas tras la ascensión al trono de la reina Victoria en 1837, y su particular repercusión en una Irlanda que a finales de la década de los 50 comenzaba a recuperarse del drama y la vergüenza de la Gran Hambruna. Citar a este respecto el despegue industrial del Ulster y la confianza creciente de una gran masa de granjeros católicos acomodados. Pero el incipiente Capitalismo Liberal también generaba una ingente cantidad de desclasados. Fenómenos como el Cartismo, el Fenianismo, el Ludismo o el amplio abanico de socialismos utópicos, eran teologías atractivas para toda una legión de agraviados del laissez/faire, de la pomposidad Imperial de la que eran partícipes los Russell y los Peel, los Disraelí y Gladstone, el pibartidismo que parecía acomodarse en Inglaterra.

Artesanos, tenderos, inteligentsia de clase media, proclives a engendrar su propio Walhala nacionalista, jacobino o socialista. Fenómeno al que Marx y 
Engels otorgaron un papel subsidiario en el inevitable advenimiento del nuevo hombre socialista, que la clase proletaria con conciencia histórica tendría que vislumbrar.

Sin embargo, para mayor desazón de Marx, fueron Proudhon, Manzini o Blanqui, los modelos que inspiraron los diferentes estallidos revolucionarios en Europa hasta la Comuna de París en 1870. Irlanda, en este sentido, no fue una excepción. En 1849, la mayoría de veteranos de 1848 se encontraba en el exilio, la cárcel o habían muerto. Algunos, como Smith O’Brien, intentaban explicarse las razones del fracaso de la insurrección, otros como James Stephen ahondaron en los postulados estratégicos de Manzini en París, mientras Mitchell propagaba la verdad patriótica de Thomas Davis en los Estados Unidos, la Meca de los exiliados y emigrantes irlandeses.

Smith O'Brien, como aquel que siente la conciencia de verse sentado sobre un reloj cósmico hacia un destino final inalterable, ofreció una versión de la fallida insurrección que a la postre se convirtió en un dogma de fe para futuros miembros de la IRB. Para O'Brien, las causas de la derrota militar son ajenas al hecho de que la absoluta mayoría de irlandeses de a pie no se viesen atraídos por los cantos de guerra patriótica contra Inglaterra. La validez del dogma de fe nacionalista nunca es puesta en cuestión, son otros irlandeses, que incapaces de descubrir las virtudes de la nueva religión política, no actúan en consecuencia.

La Iglesia católica y su oposición a los Confederados Irlandeses son el chivo expiatorio de conveniencia de O'Brien: "Fue la instrumentalización política del pueblo irlandés, por parte de la Alta Jerarquía católica, la que determinó el fracaso de la insurrección. Estoy totalmente convencido de que no fuimos derrotados por la preparación militar de Lord Harding o por el General Mac Donald, ni siquiera por el sistema de espionaje organizado por Lord Clarendon, sino por la influencia de la jerarquía católica" ( John Newsinger, p. 68).

Tras varios años de cárcel de Irlanda, John Mitchell, se dirige a Nueva York, donde junto a futuros fenianos como John O’Mahony y Michael Doheny, funda el semanario Citizen en 1853. Mitchell dedica sus esfuerzos a propagar las ideas de la Joven Irlanda entre la masa de emigrados irlandeses. Su History of Ireland (Historia de Irlanda) se convertirá tempranamente en una Biblia patriótica para la sección americana de la IRB fundada por John O'Mahony en 1858. La Fenian Brotherhood, que encuentra su inspiración en las vicisitudes de la mítica casta de nobles guerreros celtas liderada por Fiona MacCumbal. O'Mahony era como Mitchell o Davis, un gran aficionado al legendismo celta y a la Historia de Irlanda. A él se debe, por ejemplo, la traducción al inglés de mayor parte de la poética de Geoffrey Keating, de quien Davis debe tanta inspiración para la composición de sus baladas nacionales.

El historicismo nacionalista de Mitchell encontraba eco en un amplio espectro social de católicos irlandeses, que vieron como sus familiares morían de hambre mientras soldados británicos custodiaban el grano irlandés que habría de abastecer a otras partes del Imperio. Para ellos, cobraba sentido el que Mitchell defendiese la idea de que la Gran Hambruna no fuese sino una fórmula de exterminio más sofisticada que la empleada por Isabel de Inglaterra en 1590 para acabar con los rebeldes celtas de Irlanda: " En el verano de 1847, Lord Clarendon fue enviado como emisario de la Corona para acabar con la 
conquista de Irlanda, de la misma forma que Lord Mountjoy fue enviado para acabar con las guerras durante el reinado de Isabel de Inglaterra" (John Newsinger, p. 70).

Los hechos ofrecen un cuadro más complejo. La Gran Hambruna no se entiende sin la interacción de varios factores. La plaga de la patata, la estructura agraria irlandesa y el doctrinarismo laissez/faire del gobierno de Russell, que sí tomó medidas, pero del todo insuficientes para paliar tamaña catástrofe. Siendo así las cosas, el resentimiento anti-británico de los emigrados en América, era el suficiente para entender que, curiosamente, la gestación de una nueva organización militar nacionalista irlandesa tuviese su epicentro político y financiero en Estados Unidos y no en Irlanda.

El nacionalismo cultural de John Mitchell va a venir teñido de ribetes socializantes bajo el influjo de los escritos de Fintan Lalor. Este último punto pasará a ser una constante en el movimiento republicano hasta nuestros días. En resumidas cuentas, Lalor, impresionado por la hecatombe de la Gran Hambruna, argumenta que las bases, de una futura independencia nacional habría de asentarse sobre una previa reforma agraria, un ensueño de pequeños propietarios agrícolas forjado a punta de pistola. Poco antes de su muerte, en 1849, Lalor invertirá su tiempo en sentar las bases teóricas de una guerra de guerrillas que habría de forzar el cambio social en el paisaje agrario irlandés.

Mitchell, influido por sus escritos afirmaba en 1854 desde el Citizen de Nueva York que: "El movimiento de las naciones del Sur y Oeste de Europa se dirige inexorablemente hacia el Republicanismo. Europa se abre rápidamente hacia un nuevo derramamiento de sangre, en nombre del precioso e inmortal espíritu de la libertad. Hacemos un llamamiento a la clase trabajadora británica. A los hombres sin voto, sin tierra, sin derechos, que trabajan sin descanso en las minas y en las fábricas, aquellos que no tienen ningún interés en la opresión de Irlanda ni en la explotación de Asia"

(John Newsinger, p. 85)

Ello no era óbice para que Mitchell fuese un acérrimo defensor de la institución esclavista y de la propia causa confederada en la guerra de Secesión norteamericana, hasta la rendición de Lee en 1865. Mitchell, de hecho, pretendía que el esclavismo fuera introducido en Irlanda, una vez, que la República irlandesa fuese una realidad política. Ello le llevó a un enconado enfrentamiento con la Iglesia Católica irlandesa, a quien seguía acusando de haber traicionado a los Confederados Irlandeses.

En suma, las nuevas veleidades socialistas no alteraron las coordenadas nacionalistas del movimiento. Su lógica se hallaba en la necesidad de ensanchar apoyos sociales en la amplia diáspora irlandesa, particularmente en los Estados Unidos e Inglaterra. A este respecto, el propio James Stephen mantuvo esporádicos contactos con el cartismo, e incluso planteó un acercamiento al sindicalismo norteamericano de la International Working Men's Association (IWMA), pero lo cierto es que la IRB mantuvo un desinterés absoluto por el problema agrario irlandés, hasta su integración en el amplio movimiento de masas nacionalista liderado por Charles Stewart Parnell en 1880, centrando sus esfuerzos en la ejecución de un plan insurreccional que desembocase en una República Irlandesa. El ex/ feniano y arquitecto de La 
Guerra por la Tierra (Land War) Michael Davitt recordaba con disgusto en 1881, que la IRB "fue culpable de dar a los terratenientes irlandeses cerca de veinte años de paz agraria"

Mientras tanto, James Stephen seguía manteniendo los contactos con revolucionarios románticos europeos en su exilio parisino. Conoció a fondo la estrategia de conspiración de Manzini a través de miembros de la Joven Italia, y se involucró directamente en los intentos de acabar con el régimen de Luis Bonaparte en Francia. En 1851, decía Stephen, "los italianos han perfeccionado sobremanera las teorías conspiradoras. Pienso, sin ninguna reserva, que son los métodos estratégicos a seguir". En 1856, regresa a Irlanda, donde según sus propias palabras, encuentra un país políticamente muerto. A todos los efectos, "una provincia reconquistada por Inglaterra". Stephen logra el apoyo político y financiero del exilio americano para fundar una nueva vanguardia patriótica. El 17 de marzo, día de San Patricio, se crea la Irish Republican Brotherhood (IRB).

La idea genérica de la estrategia revolucionaria de Stephen era que la IRB debía de tomar ventaja de que Inglaterra se viese envuelta en conflictos exteriores, así como sellar, en lo posible, una alianza política con el movimiento obrero británico. Un conflicto Imperial vaciaría de tropas de la Corona Irlanda, y haría posible el triunfo de una insurrección feniana. Hasta entonces, la IRB orientaría sus recursos a extender una red de apoyo clandestina, tanto en Irlanda como en Inglaterra, hasta que llegase el momento de la insurrección.

A principios de los sesenta la IRB logra reclutar a varias decenas de miles de militantes. R. V. Comerford calcula que para 1865, los miembros de la IRB en las islas británicas podrían ascender a 50.000 (R.V. Comerford, p. 81). La IRB aglutinaría a amplios sectores de la sociedad irlandesa que se situarían fuera de los márgenes de prosperidad social y económica de la emergente clase media agraria irlandesa, bajo el pertrecho de la creciente influencia de la Iglesia católica y cuya cabeza más visible sería el cardenal Paul Cullen.

De los más de 1.100 detenidos baja la suspensión del Habeas Corpus entre 1866 y 1868, acusados de pertenencia a la organización, se calcula que un $50 \%$ eran artesanos o obreros cualificados, mientras que el resto eran tenderos, baja jerarquía eclesial católica o maestros de escuela. (R.V. Comerford, p. 82). Incluso James Stephen reconocía que la IRB estaba mayoritariamente compuesta "por los hijos de los granjeros, mecánicos, trabajadores y tenderos". Es decir, pequeña burguesía desafecta ante las nuevas formas de transformación social y económica que el capitalismo liberal de época victoriana imponía en las islas británicas.

A este respecto, llama la atención el hecho de que el órgano de expresión de la IRB en Irlanda, The Irish People (el pueblo irlandés) en 1863, jamás hiciese público un programa social definido. Las páginas del Irish People reflejaban una mezcla de mesianismo narcisista y resentimiento social no oculto, dirigido contra Inglaterra, la aristocracia protestante, pero fundamentalmente contra la clase media agraria católica irlandesa, a la que se acusaba de "egoísmo y falta de espíritu nacional" (R. V. Comerford, p. 84).

Todos los males de la sociedad irlandesa habrían de diluirse en el paraíso patriótico republicano, en el que la IRB, como legítimo "intérprete del espíritu nacional", tendría, lógicamente, la última palabra. La proclamación del 
Gobierno Provisional de la República de marzo de 1867, comenzaba con el enunciado de "Nosotros, pueblo de Irlanda al mundo!!!". La IRB, pueblo de Irlanda, apelaba al más alto Tribunal de Justicia "para dar fe de la nobleza y la justicia de nuestra causa". Ese Tribunal de Justicia era la Historia, "testigo de nuestros sufrimientos a lo largo de los siglos". De tal guisa que la IRB, proclamó una fantasmal República irlandesa, con la Historia como más fiel aliado e ignorando que la gran mayoría de católicos irlandeses (ninguneando además a los protestantes del Ulster) se mostraba más proclive a sostener con donaciones al emergente poder político de la Iglesia Católica "para paliar sus sufrimientos", que ofrecer sus servicios patrióticos a la vanguardia feniana.

De ahí que las relaciones entre el movimiento feniano y la Iglesia Católica fueran tirantes o cuando menos conflictivas. No obstante, el cuadro ofrecido por el feniano John O'Leary, en sus Recollections of Fenians and Fenianism (1882), y su famosa aseveración de que "pretendíamos acabar con el dictado clerical, y lo logramos" es bastante incierto. La IRB nunca puso en cuestión la preeminencia social de la Iglesia católica en Irlanda. La gran a mayoría de sus cuadros hacían alarde de un gran fervor católico, y el apoyo eclesial era bienvenido cuando la ocasión se presentaba. Como en el funeral del Confederado Macmanus en el Dublín de 1861, que contó con la connivencia, que no el apoyo explícito del Cardenal Paul Cullen. Como diría el feniano Kickham: "jamás dijimos una palabra en contra de los curas como ministros de religión , pero cuestionamos, y lo seguimos haciendo, el derecho de la Iglesia a dictar criterio político alguno a nuestro pueblo" ( R. V. Comerford, p. 89).

El principal temor de la Iglesia Católica irlandesa era que, efectivamente, el fenianismo pudiese ofrecerse como religión alternativa a la suya propia, tanto en la esfera política como en lo social. El Cardenal Cullen, que no era menos anti-protestante o anti-británico que la que los fenianos irlandeses, veía a estos bajo el prisma del Republicanismo revolucionario ateo del continente, aunque a este respecto la IRB era bastante más conservadora que el resto de los hijos de Blanqui o Manzini en Europa, a excepción quizás del movimiento de liberación nacional polaco. El Cardenal Cullen presenció en Roma, los acontecimientos revolucionarios que llevaron a Pio IX a huir de la ciudad en 1848. El cuadro, descrito como "un calvario penitente", finaliza con una advertencia: "Si algún día alguien intentase recortar los derechos y libertades de la Iglesia Católica en Irlanda, ello no vendría del gobierno inglés, ni del sentimiento anti- papista en Inglaterra, sino de los revolucionarios y ateos nacionalistas en Irlanda" (R. F. Foster, p. 345).

No obstante, la Iglesia católica mostraba una actitud de cierta ambivalencia con los guerreros celtas de la IRB. El ultranacionalismo anglófobo de éstos incomodaba, ciertamente, a una institución, que como amplios sectores de la Irlanda católica, comenzaba a beneficiarse, por primera vez, de su Unión con Inglaterra, pero que no podía hacer oídos sordos al hecho de que, además, de "patriotas", los fenianos hacían gala de un fervor católico inusitado.

Todos ellos, incluidos los mártires de Manchester, se encomendaban a Dios antes de morir por Irlanda. Todo indica que la presencia de protestantes en el movimiento feniano, como la de John O'Leary, apodado el "pagano", eran excepcionales. O'Leary recuerda que "ciertamente no nos veíamos como parte integrante de un movimiento secular, sino como una minoría tolerada dentro de 
un movimiento esencialmente católico" ( $\mathrm{O}^{\prime}$ Leary, p. 53). La presencia de protestantes del Ulster era inexistente en el movimiento, y la pauta, en general era la manifestada por Jeremiah O’Donnovan Rossa en las memorias escritas en una cárcel inglesa: "La mayoría de militantes fenianos sentían que combatiendo el protestantismo, estaban luchando contra Inglaterra, y que luchando por el catolicismo, estaban luchando por Inglaterra "(Jeremiah O’Donnovan Rossa, p. 18).

Lo cierto es que para 1865 la posibilidad real de una insurrección feniana en Irlanda era tomada en serio por el propio Gobierno británico. Miles de fenianos combatieron en la guerra de Secesión en regimientos autónomos bajo la bandera verde de Erin. La guerra de Secesión reforzó el sentimiento de vanguardia patriótica, y sobre todo ofreció a la IRB cuadros militares preparados, prestos al combate contra Inglaterra. James Stephen, al que muchos consideraban en la organización como un déspota, tenía la firme convicción de que había llegado la hora de golpear al Imperio en su retaguardia, antes de comenzar una insurrección general en Irlanda, y para ello contaba con los socios americanos, la fiel militancia en Inglaterra, y una poderosa organización construida con un incesante esfuerzo desde 1858.

Los planes de Stephen comienzan a truncarse en septiembre de 1865, cuando las autoridades británicas del Castillo de Dublín y el RIC (Royal Irish Constabulary) clausuran el periódico feniano The Irish People. A este hecho le sucederá la suspensión del Habeas Corpus en febrero de 1866 y el arresto de centenares de miembros de la IRB. Stephen es acusado de negligencia por amplios sectores del movimiento en Estados Unidos y se ve forzado a abandonar la organización. La Fenian Brotherhood pretende resarcirse de los sucesivos golpes a través de una fallida intentona de invasión canadiense, un gesto insurreccional que es abortado a mediados de ese año. El fracaso abre una nueva crisis en el seno de la organización, saldada con el relevo del poder de O'Mahony y de toda la antigua generación de Confederados . En adelante, la Fenian Brotherhood tomará el nombre de Clan na Gael.

En Irlanda, una IRB descabezada y en desbandada, pretende reconvertir su aislamiento y debilidad en virtuosismo e iluminismo patriótico. William Pigot, testigo de excepción en la insurrección feniana, recuerda cómo los fenianos: "abarrotaban los confesionarios para hace las paces con Dios, antes de dar su vida por la sagrada libertad de Irlanda" (John Newsinger, p. 65).

El 5 de marzo de 1867 la IRB proclama un Gobierno Provisional Republicano, que va seguida de una intermitente lucha de guerrillas, ahogada en la falta de recursos humanos (no más de varios centenares de miembros), una absoluta descoordinación y ningún objetivo político definido. La fortaleza de la IRB se va diluyendo en intermitentes atentados terroristas, que conmocionan a la opinión pública británica y fuerzan al gobierno Tory de Disraeli a tomar medidas de excepción tanto en Irlanda como en Inglaterra. (D. George Boyce, p. 78) En una famosa homilía del obispo de Kerry en 1867 rechazaba la violencia terrorista feniana afirmando que: "La eternidad en el fuego del infierno no es suficiente para castigarlos".

El 17 de septiembre de 1867, William Allen, Michael Larkin y Michael O’Brien son sentenciados a morir ahorcados para asesinar a un sargento de policía británico al intentar liberar a dos líderes fenianos encarcelados en Manchester. 
El alegato patriótico de todos ellos, instantes antes de morir en la horca, un 23 de noviembre de 1867, les convertirá en los primeros mártires del movimiento feniano y en icono de culto nacionalista para sucesivas generaciones republicanas. El fervor patriótico redentor va intrínsicamente unido a una profusión de fe católica, lo que refuerza el carácter sacramental y religioso de la causa nacionalista.

Michael Davitt alegaba ser "un patriota que muere por Dios y por Irlanda", mientras que Michael O'Brien se consolaba con la certeza de que "Mi redentor recibió una muerte aún más vergonzosa, de la manera en que sólo el hombre sabe darla. Que Dios me perdone y reciba su gloria en el cielo. Ruego encarecidamente a Dios, que mis compatriotas en América olviden sus diferencias en nombre de Irlanda y su libertad". William Allen deja aún más clara la dimensión sacramental y religiosa de la causa nacionalista: "Que Dios salve nuestras almas y libre a Irlanda de su sufrimiento: ¡Dios salve a Irlanda! (T. W. Moody, p. 78).

Dios Salve Irlanda uno de los más conocidos lemas del movimiento republicano contemporáneo. El lema sintetiza el mensaje para futuras generaciones de patriotas fenianos. El soldado nacionalista en armas, y su muerte en guerra contra Inglaterra, garantiza la supervivencia de la nación irlandesa. De ese nosotros irlandés, esbozado ya en la poética de Davis.

Las ejecuciones generaron una general repulsa anti-inglesa en Irlanda, y muchos intelectuales liberales, como el propio John Stuart Mill, se posicionaron públicamente en contra de las ejecuciones. Sin embargo, las críticas a las medidas de Disraeli se acallaron tras el atentado de Clerkenweell, en diciembre de 1867, en el que más de una decena de ciudadanos civiles ingleses perdieron la vida por una bomba de la IRB. La organización iniciará a partir de entonces, un lento pero irreversible declinar, hasta que en 1873, una nueva Constitución de la organización, rechaza la utilización de métodos violentos, "hasta que no sean apoyados por una mayoría de irlandeses".

Tras la política de pan y mantequilla instigada por el gobierno liberal de Gladstone, a partir de 1870, garantizando la libre compra/venta de propiedades agrarias a los granjeros católicos irlandeses e introduciendo medidas legislativas que minaban sobre manera los abusos y arbitrariedades de los terratenientes protestantes sobre el pago de rentas (complementada por una nueva ley agraria en 1881) la vida política irlandesa comenzará a deslizarse por otros derroteros. La omnipresente figura del Cardenal Cullen pierde fuerza, hasta su muerte en 1878, y el terrorismo nacionalista feniano sólo hace esporádicas apariciones, caso de los asesinatos del Parque de Phoenix en 1882, donde el secretario y subsecretario de la Corona en Irlanda fueron asesinados por una facción escindida de la IRB, Los Invencibles.

El principal movimiento socio/político en este periodo nacerá al calor del reformismo liberal gladstoniano, la Liga por la Tierra (The Land League) de Isaac Butt y Michael Davitt. Se trata de un radicalismo agrario de nuevo cuño, que pretende acabar con el poder de los terratenientes irlandeses y en el que numerosos miembros de la IRB encontrarán acomodo. La Liga por la Tierra tomará el nombre de The Irish National League (La Liga Nacional irlandesa) en 1879, cuando se integra en la Nueva Andadura encabezada por Parnell. El mismo movimiento que aunando antigua retórica feniana, radicalismo agrario y 
posibilismo constitucionalista arrancó la promesa liberal británica de una futurible Irlanda autónoma, tras el primer intento fallido en 1886.

Cabezas visibles de la IRB como O'Leary, Sullivan o John Devoy, apoyaron desde 1878, al recién nombrado líder del partido autonomista irlandés, Charles Stewart Parnell, bautizado como el Rey sin Corona de Irlanda. El hombre que encabezó el primer movimiento de masas nacionalista irlandés y dominó la vida política irlandesa hasta su caída en desgracia y muerte en 1891.

Haciendo repaso de los logros de la IRB en 1889, James Stephen consideraba imprescindible la violencia feniana en la década de los 60: "Sin ella, el sentimiento nacional no sería tan poderoso hoy día. La IRB salvó la causa de la nacionalidad irlandesa de una destrucción inmediata. Sin ella, una generación entera irlandesa habría caído en la vergüenza de no rebelarse contra la supremacía inglesa. Sin ella el pueblo irlandés hubiera asentido acomodarse al poder británico. Pero el movimiento feniano rescató a la nación de su destrucción, y mantuvo en pie el puente que separa a Inglaterra e Irlanda" ( George Boyce, p. 123).

La violencia nacionalista es, por lo tanto, lo que en última instancia mantiene viva a la nación ahistórica irlandesa, y la que marca la idea del necesario antagonismo entre Inglaterra e Irlanda. Idea central en el drama y la poética del sucesor de Thomas Davis, y el más ilustre de todos los fenianos, William Butler Yeats.

\section{BIBLIOGRAFÍA:}

ANDERSON, B. (1991), Comunidades Imaginadas (Reflexiones sobre el origen y difusión del nacionalismo), México, Fondo de Cultura Económica.

AZURMENDI, M. (1998), La Herida Patriótica, Madrid, Taurus.

BAROJA, P. (1978), Las Inquietudes de Shanti Andia, Barcelona, Planeta.

BERLIN, I. (1995), Las raíces del romanticismo, Madrid, Santillana.

BOYCE, G. (1990), Nineteenth Century Ireland (The Search for Stability), Dublin, Gill and Macmillan.

COMERFORD, R. V. (1985), The Fenians in context, Dublin, Wolfound.

DAVIS, R. (1987), The Young Ireland Movement, Dublin, Gill and Macmillan.

DUFFY, G. (1998), Thomas Davis (Literary and Historical Essays), England, Woodstock Books. FOSTER, R. (1989), Modern Ireland (1600-1972), London, Penguin Books.

LEERSEN, J. (1996), Mere Irish and Fior- Gael, Cork, Cork University Press.

MC COURT, F. (1996), Angela's Ashes (A memoir of a Chilhood), London, Harper Collins.

NEWSINGER, J. (1994), Fenianism in Mid Victorian Britain, Nueva York, Pluto Press.

MOODY, T. W. (1968), The Fenian Movement, Cork, Mercier Press.

MOLONY, J. N. (1995), A soul came to Ireland, Dublin, Geography Publicatons.

O’BRIEN, C. C. (1972), States of Ireland, London, Hutchinson.

O'DONNOVAN, R. (1967), My years in English Jails, London, Trailee.

O'LEARY, J. (1986), Recollections of Fenians and Fenianism, London, Downey.

O'RIORDAN, M. (1990), The Gaelic Mind and The Collapse of The Gaelic World, Cork, Cork University Press.

POEMS OF THOMAS MOORE, (1982), Dublin, Educational Limited Company, Dublin. 